\title{
FORMAS NARRATIVAS em SAMUEL RAWEt
}

http://dx.doi.org/10.11606/issn.2237-1184.v0i29p62-71

Jaime Ginzburg

Universidade de São Paulo (USP)

\section{RESUMO}

Neste artigo são estudados três contos de Samuel Rawet publicados em seu livro Os sete sonhos. Através das reflexões, podemos observar o emprego de recursos oníricos, suspendendo os limites entre imaginação e realidade. Nessas narrativas, a elipse é muito importante, assim como estratégias estéticas de choque. Para fundamentar o artigo, consideramos trabalhos de Berta Waldman e Rosana Kohl Bines sobre o autor.

\section{ABSTRACT}

We discuss in this article three short stories from Samuel Rawet's book Os sete sonhos. According to our approach, we can find a dreamlike language, blurring boundaries between imagination and reality. In these narratives, Ellipse is very important, as much as aesthetics of shock. To develop our reflection, we focused on critical essays written by Berta Waldman and Rosana Kohl Bines.

\section{PALAVRAS-CHAVE:}

Samuel Rawet; narrativa; elipse; estética do choque.

\section{KEYWORDS}

Samuel Rawet; narrative; ellipse; aesthetics of shock. 


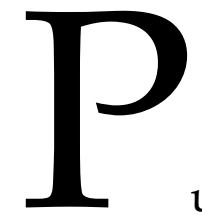

ublicado em 1967, o livro Os sete sonhos, escrito por Samuel Rawet ${ }^{1}$, inclui dezoito contos. Por suas especificidades temáticas e formais, a obra consiste em um desafio para a crítica e a historiografia literárias. Rawet, escritor pouco conhecido e estudado, publicou obras desde os anos 50 até o início dos anos 80, desenvolvendo uma trajetória singular na literatura brasileira, escrevendo contos, novelas e ensaios.

Este artigo é dedicado ao estudo de três contos desse livro: "Raiz quadrada de menos um", "Os sete sonhos" e "O encontro". Com esses textos, é possível realizar um movimento de aproximação das especificidades de Rawet, de modo a elaborar, ainda que de modo incipiente, uma proposição referente à relevância do autor.

\section{"Raiz quadrada de menos um"}

O narrador desse conto se constitui como um escritor, que desenvolve um processo de planejamento de sua criação. Entre os elementos apresentados nesse planejamento, está um esboço de uma narrativa sobre oniromancia. Dois personagens, designados como "tolo" e "sábio" interagem, a partir do interesse do primeiro em que o segundo o ajude com seus sonhos, que seriam excessivos, constituindo um "transbordamento onírico". ${ }^{2}$ Surge um conflito entre os personagens, que leva o sábio a decidir castigar o tolo, levando-o à insanidade. A estratégia utilizada é a de "tornar real seu mundo onírico e seus temores"3, eliminando a diferenciação entre sonhos e realidade. Ao apresentar essa estratégia do sábio, o narrador afirma: "Pretendo me estender bastante sobre este ponto que me parece fértil para a ficção" ${ }^{4}$

São três níveis de elaboração imaginativa que se articulam: Samuel Rawet criando uma narrativa sobre um escritor; este criando uma segunda narrativa, sobre o tolo e o sábio; e este último suspendendo a distinção, na vida do tolo, entre sonho e realidade. É estabelecida uma relação entre o trabalho criativo do escritor e a matéria dos sonhos do tolo. Ao chamar a atenção para a exploração ficcional do assunto, o escritor criado por Rawet

\footnotetext{
${ }^{1}$ RAWET, Samuel. Contos e novelas reunidos. Rio de Janeiro: Civilização brasileira, 2004.

2 Idem, ibidem, p. 167.

${ }^{3} I d$., ib., p. 168.

${ }^{4} I d .$, ib., ib.
} 
articula diretamente duas formas de pensamento, a ficção e o sonho. Neste ponto da enunciação, a vida onírica do tolo é considerada relevante para a criação de que se ocupa esse escritor. A sua literatura se ocuparia das possibilidades de significação da linguagem onírica.

O desejo do sábio, tornar a matéria onírica uma realidade, remete a um texto de Jorge Luis Borges, "As ruínas circulares". O protagonista desse conto tinha como objetivo "sonhar um homem: queria sonhá-lo com integridade minuciosa e impô-lo à realidade". ${ }^{5}$ Afinidades eletivas entre contos de Borges e de Rawet podem ser encontradas com frequência. A ultrapassagem do limite do sonho, em passagem para a realidade, configura um desafio para a percepção humana. Uma vez suspenso esse limite, a interação com o mundo está arriscada a se afastar das percepções partilhadas socialmente, isolando o sujeito em sua maneira única de olhar o que está à sua volta. O sábio quer agir de modo destrutivo sobre o tolo; este, depois de sofrer com o excesso de sonhos, ficaria exposto a um mundo sem limite. Afirma o narrador: "Com esses elementos o ilustre oniromante cria um clima infernal para seu ex-cliente, deixando-o num estado de pura irrealidade". ${ }^{6}$ A suspensão do limite entre sonhos e realidade é caracterizada como uma catástrofe, em que a irrealidade ocupa de forma total a existência do tolo.

Em parte, essa narrativa remete a uma estrutura de parábola, como se contivesse uma espécie de saber: aquele que não sabe lidar com os próprios sonhos acaba por perder-se dentro deles; ou talvez, por outro ângulo, aquele que confia a outro "todos os episódios de sua vida" 7 se expõe a uma situação de vulnerabilidade e acaba por ser destruído. A estória do tolo e do sábio poderia ser interpretada, nesse sentido, como uma orientação para que os seres humanos saibam resolver, por si mesmos, os sofrimentos que seus sonhos causam; ou ainda como uma demonstração cética de que confiar em outros, mesmo que sejam considerados sábios, é um risco que pode levar ao aniquilamento.

No entanto, o escritor criado por Rawet aborda a interação entre esses personagens sem um esforço de síntese. Trata-se de um esboço, em que as ideias ainda não ganharam forma definitiva. O escritor sustenta, de modo interrogativo: "Há possibilidade de vida num clima de transição entre o real e o irreal? Optará o tolo pela irrealidade de sonhos tornados realidade?". ${ }^{8}$ Com os questionamentos, o narrador se afasta da convenção da parábola para escolher um discurso meditativo, que não encontra acomodação. É como se o narrador estivesse explorando possibilidades,

\footnotetext{
${ }^{5}$ BORGES, Jorge Luis. Fiç̧ões. Porto Alegre: Globo, 1972. p. 60.

${ }^{6}$ RAWET, Samuel. Op.cit., p .168.

${ }^{7}$ Idem, ibidem, p. 168.

${ }^{8} I d$., ib., p. 169.
} 
imaginando hipóteses de criação, sem ter clareza suficiente sobre como delimitar seus personagens.

A pergunta "Há possibilidade de vida num clima de transição entre o real e o irreal?", especificamente, desperta uma reflexão, que pode ser ampla e instigante, sobre a relação entre vida e realidade. Seria possível viver quando não é certo o que é ou não real? Como lembra Irene Klein, na ficção, não se trata de definir certezas, mas de ultrapassar e transgredir os parâmetros do que definimos como real. ${ }^{9}$ A compreensão que temos de nossas próprias vidas depende de termos certezas quanto a nossas percepções? Em caso positivo, o que ocorre quando essas certezas são eliminadas?

Além da estória do tolo e do sábio, existe um interesse do escritor por uma biografia de Sócrates. O narrador integra esses dois assuntos, pensando em uma "fusão em um conto ou novela". ${ }^{10}$ Em "Raiz quadrada de menos um", essa fusão não está delimitada, e em um único ponto é exposta uma razão para que ela fosse realizada: "O que me preocupa mesmo é o real". ${ }^{11}$ Tanto na estória do tolo, como na biografia de Sócrates, o narrador está atento ao "real". O título do conto, que se refere a um problema da Matemática, contribui para essa ênfase, uma vez que, para pensar em um cálculo de raiz quadrada de um número negativo, é necessário ultrapassar conhecimentos tradicionais de álgebra ${ }^{12}$ e adentrar no campo dos números complexos. Metaforicamente, a expressão "menos um" pode fazer referência a uma negatividade constitutiva do sujeito. Essa concepção negativa corresponderia a uma vida na "irrealidade", como ocorre com o tolo em razão da vingança do sábio.

\section{"Os sete sonhos"}

Esse segundo conto apresenta, como o anterior, afinidades com "As ruínas circulares". No conto de Borges, o sonhador lida com detalhes do processo de criação onírica de um homem, de tal modo que constitui uma ambiguidade entre as propriedades espontâneas e involuntárias esperadas de um sonho, e as determinações necessárias para o cumprimento de um objetivo. Essa ambiguidade é desenvolvida em alta potência em "Os sete sonhos". Chama a atenção que o protagonista, um sonhador, se move em seu universo onírico. Assim como em "As ruínas circulares", o conto de Rawet propõe uma "crítica à lógica racional moderna", de modo a questionar a respeito de "modos alternativos de experiência". ${ }^{13}$

\footnotetext{
${ }^{9}$ KLEIN, Irene. La narración. Buenos Aires: Eudeba, 2009, p. 88.

${ }^{10}$ RAWET, Samuel. Op.cit., p.167.

${ }^{11}$ Idem, ibidem, p. 170.

${ }^{12}$ MILIES, César Polcino. Breve história da álgebra abstrata. Salvador: UFBA, 2004, p. 38.

${ }^{13}$ OLMOS, Ana Cecília. Por que ler Borges. São Paulo: Globo, 2008, p. 81.
} 
Em um importante momento do conto, o narrador diz: "A questão intrigava-o ainda mais porque no sexto sonho, já de volta, tinha um argumento do último e a reminiscência dos cinco anteriores" ${ }^{14}$ Essa caracterização do processo sugere que existe um movimento, com etapas nítidas e consequências determinadas.

Sendo o sonho, de acordo com Freud, um processo que envolve "conteúdos dos pensamentos pré-conscientes e do desejo reprimido"15, sem operar com uma temporalidade linear, como seria possível transformar a vida onírica em uma série numerada que, para além de ser delineada em uma ordem, é regida por uma memória que delimita com clareza o que já se passou?

Sem apresentar explicações ou justificativas, o conto explora as condições de elaboração do material onírico através de uma ambiguidade: ora os conteúdos parecem corresponder a expectativas determinadas, ora surgem como forças imprevisíveis. Em alguns momentos, o sujeito está distanciado de seu sonho, como se pudesse avalia-lo criticamente; por exemplo, quando o sonhador se refere à "realidade concreta de cada etapa". ${ }^{16} \mathrm{~A}$ presença da expressão "realidade concreta" remonta ao modo como o sábio se vingou do tolo, em "Raiz quadrada de menos um". Nos dois casos, os sonhos e a realidade se integram em vivências, sendo suspensa a diferenciação clara entre eles.

O conto apresenta manifestações oníricas diversas. Berta Waldman, comentando a ficção de Rawet, afirma que seus contos são como "criptonarrativas que transformam o leitor em releitor e anunciam constantemente que o sentido não está à tona, e que há um "resto" difícil de submeter". ${ }^{17}$ Com efeito, no caso desse conto específico, é como se estivéssemos diante de fragmentos de criptonarrativas no interior de uma criptonarrativa maior, que não admite síntese. A narração indica a movimentação do sujeito entre os sonhos que constituem um conjunto de sete, conforme define o título. A combinação entre a diversidade de imagens e o caráter não linear da movimentação resulta em uma exposição elíptica e fragmentária, na qual os limites entre os momentos de visão não são inteiramente precisos, nem a duração de cada percepção.

Várias imagens apelam, ostensivamente, a sentidos corporais - a visão, o tato e a audição. Três aspectos entre as vivências oníricas merecem destaque:

\footnotetext{
${ }^{14}$ RAWET, Samuel. Op.cit., p.144.

${ }^{15}$ FREUD, Sigmund. "Alguns complementos à Interpretação dos sonhos". In: Idem. O eu e o id,

"Autobiografia" e outros textos (1923-1925). São Paulo: Companhia das letras, 2011, p.324.

${ }^{16}$ RAWET, Samuel. Op.cit., p.143.

17 WALDMAN, Berta. Entre passos e rastros. São Paulo: Perspectiva/Fapesp, 2003, p. 72.
} 
a) A violência, que se expressa no golpe com o joelho na boca de um homem;

b) A sexualidade, exposta diretamente em uma cena de sexo oral entre dois homens;

c) A configuração abstrata do mundo, observada nas imagens de retângulos e quadrados.

Além destas, cabe mencionar a cena inquietante de uma onça dando uma patada em uma criança de dois anos, a imagem de um "sol de carne"18, e as referências a um fetiche de coprofilia. Os casos de (a) e (b) estão em convergência, pois a narração sugere que o sujeito vivencia um mal-estar após a realização do ato sexual, o que motivaria a agressão do homem que nele praticou a felação. Por outro lado, a intensidade física dessas imagens contrasta com o caso de (c), em que a intensidade das sensações corporais é substituída por formas geométricas. Esse contraste indica que o sonhador não tem uma única maneira de sonhar, mas que ele explora diferentes condições de vivências oníricas. Isso acentua a fragmentação do processo. As ocorrências das imagens de uma cadeira de balanço e de um moinho d'água instabilizam ainda mais essas vivências, como se a percepção de esboços de narrativas fosse substituída por imagens isoladas.

Apesar das indicações claras de prazer sexual do sujeito, o contexto em que a cena do ato sexual é exposta não contribui para uma atmosfera erótica. Ao contrário, o sexo integra um universo marcado por opressão, em que o prazer é sucedido de imediato pela emergência da violência. $O$ fato de que o golpe é dado pelo sujeito especificamente na boca do outro é expressivo, pois foi a boca que provocou o prazer, na felação. A violência dentro do sonho sugere uma espécie de punição, como se o ato homossexual fosse governado por uma interdição, que visualmente o associa à contemplação de fezes.

Se os elementos (a) e (b) estão de fato configurados em um contexto de repressão sexual, as imagens em (c) apontam para um horizonte diferente. Às vivências incômodas do corpo, se opõem as imagens geométricas do mundo, segundo as quais existe uma ordem que delimita a percepção. No entanto, as formas de retângulos e quadrados não produzem harmonia, e não pacificam a aflição do sujeito sonhador. Prevalece, ao longo do conto, a dificuldade de lidar com o corpo como uma matéria constitutiva importante nos sonhos.

Uma passagem que exemplifica isso é a "busca de uma dor mais violenta que lhe sugerisse algo entre aquilo e a cadeira de balanço, entre a

${ }^{18}$ RAWET, Samuel. Op.cit., p.147. 
cadeira de balanço e o moinho d'água". ${ }^{19}$ As vivências oníricas estariam sendo conduzidas na direção de uma aproximação da dor. Segundo o narrador, existiria uma proporção entre a intensidade da dor e a necessidade de transformar suas vivências. É como se o sujeito procurasse deliberadamente o sofrimento, pois isso levaria a mudar sua vida.

A imagem de um homem que se aproxima do sujeito, por trás, pode ser observada como uma ameaça, um risco de violência, mas também, em sua polissemia, como uma potência erótica, uma fantasia homossexual. Essa imagem não é desenvolvida o suficiente para que fique claro para o leitor de que exatamente se trata. Especificamente por essa razão, em sua construção elíptica, ela tem um efeito liminar, em que a possibilidade do erotismo é, ao mesmo tempo, uma possibilidade de risco.

Em sua parte final, o conto explora a ambiguidade de modo mais abrangente, articulando elementos dos sonhos com informações que, conforme é sugerido, se referem a fatos concretos da vida cotidiana do sujeito. Essa referência a uma realidade que se distingue da vida onírica, no entanto, é substituída, na última frase, em um movimento similar ao da abertura do conto, pelo anúncio de outros sete sonhos, "mas sonhos descendentes, negativos, impregnados de sua ação cotidiana". ${ }^{20}$ Os adjetivos "descendentes" e "negativos", a rigor, poderiam caracterizar, pelo menos em parte, os sonhos narrados ao longo do conto. A presença da palavra "mas" indica que existe uma diferença substancial entre os anteriores e os que estão anunciados como novos, o que pode causar inquietação. Seriam, talvez, sonhos inteiramente negativos, nos quais o prazer não tenha qualquer presença?

\section{"O encontro"}

Em "Raiz quadrada de menos um", a narrativa do tolo e do sábio sugere que a perda da distinção entre sonhos e realidade pode ser catastrófica. Em "Os sete sonhos", a vida onírica é tratada com ambiguidade, entre a espontaneidade e a determinação, entre a obtenção de prazer e a busca da dor. "O encontro" permite refletir sobre o ato de fantasiar.

O protagonista é caracterizado por sentir prazer ao pensar em violência ou praticá-la. Esse prazer não se restringe a um sentimento de satisfação; ele se manifesta explicitamente como sexual. No terceiro parágrafo do conto, é apresentado um "serviço" 21 pago; embora a narração apresente essa informação de modo elíptico, é possível inferir que se trata da encomenda de um assassinato, o que acaba sendo confirmado ao final do conto.

\footnotetext{
${ }^{19}$ Idem, ibidem, p.146.

${ }^{20}$ RAWET, Samuel. Op.cit., p.148.

${ }^{21}$ Idem, ibidem, p.156.
} 
De acordo com o narrador, quando é efetuado o pagamento de metade do valor combinado, o protagonista é tomado de ódio pelo seu alvo, mesmo sem conhecê-lo. O terceiro parágrafo explicita, sem sutileza e com intensidade, a força da antecipação mental do ato de violência a ser cometido. A cadeia de associações de elementos, das notas de dinheiro até a ejaculação, expõe uma continuidade direta entre o assassinato e o prazer genital. Embora a violência tenha uma causa explicada - um serviço encomendado - ela é atravessada pelo prazer individual do matador.

Ao guardar as notas de dinheiro, o protagonista toca no próprio pênis. Uma rememoração de ações similares à que planeja faz com que tenha uma ereção e seu corpo fique tenso. Ele pensa em mulheres que poderiam estar próximas, como se um corpo feminino pudesse aliviar a tensão; mas, em seguida, pensa que essa excitação "não pedia afagos e beijos", apenas uma "ejaculação intensa". ${ }^{22}$

O fato de que o ódio surge no contato com o dinheiro, independente de quem seja especificamente o alvo, indica que odiar seria uma circunstância que pode se mover de uma situação a outra, variando o objeto, e que seu fundamento está no prazer daquele que odeia, e não em uma frustração ou um sofrimento.

Com a mesma convicção com que constituiu o ódio, ao ver a face do homem que vai matar, o protagonista "principiou a amá-lo" 23. Guardada a polissemia da expressão "amá-lo", que pode ser interpretada de muitas maneiras, não há dúvida de que, semanticamente, ela está em oposição com a manifestação anterior de ódio. Essa transformação, motivada unicamente por uma visão, causa estranheza.

A partir do quinto parágrafo, o narrador passa a se referir ao assassino e ao seu alvo como dois personagens que desempenham ações comuns, o que contribui para essa estranheza. Ao invés de firmar um distanciamento entre eles, o narrador os aproxima pelos verbos "atravessaram", "deixaram", "tomaram", "avançariam"24. É como se aos dois personagens coubesse um movimento articulado, no qual a perseguição é observada como se fosse uma coreografia com movimentos coordenados. Entre o momento em que recebe as notas e os períodos de insônia, o assassino estabelece seu ódio; a partir do ponto em que vê o outro homem, define que sente amor por ele.

Nada disso resulta de interações, conversas, de nenhuma aproximação concreta. A decisão de aceitar o serviço motiva uma fantasia; a visão do homem, outra. Nos dois casos, é o próprio protagonista, e não qualquer interação, que define seus sentimentos. Tanto o ódio como o

\footnotetext{
${ }^{22} I d .$, ib.., p. 156.

${ }^{23} I d .$, ib., p. 157.

${ }^{24} I d$., ib., ib.
} 
amor prescindem de estarem motivados por ações do outro, que ao longo do conto permanece alheio a tudo o que se passa na mente do assassino.

A cena final é apresentada da seguinte maneira: "E se aproximou do tipo que o esperava tendo já na mão o brilho de uma faca, lâmina larga, dois gumes, e ainda conseguiu abraçá-lo e beijá-lo antes que um reflexo de prata e sangue lhe tingisse os olhos" ${ }^{25}$ A narração elíptica não deixa claro quem foi atingido pela faca, nem de qual deles vem o sangue, ou ainda se os dois se feriram. A ambiguidade permite a percepção, por um lado, de acordo com os momentos precedentes, de que o assassino usou a faca para matar o homem que buscava. No entanto, seria aceitável, por outro lado, a hipótese de que este usou a faca para se defender, e com isso atingiu o corpo do protagonista. A polissemia do texto não permite decidir com certeza qual o desfecho do enredo.

Nessa cena, cabe destacar o trecho que diz "ainda conseguiu abraçálo e beijá-lo". O ato violento é ao mesmo tempo uma manifestação de desejo. Se o ódio move o protagonista para o assassinato, o amor enunciado o move ao beijo. A cena final leva ao paroxismo o que estava anunciado no trecho sobre masturbação: com a destruição do outro, o protagonista sente um gozo. O objeto do desejo de destruição é também, nesse momento, simultaneamente, um objeto de desejo amoroso. Nesse aspecto, o conto pode ser aproximado da tela "Two figures", de Francis Bacon, de 1953, na qual dois corpos estão desenhados em uma posição que, ambiguamente, pode corresponder a um ato sexual ou a uma luta corpo a corpo. ${ }^{26}$

\section{Considerações finais}

De acordo com Rosana Kohl Bines, Samuel Rawet criou uma "literatura do desregramento" 27 , em que "a parataxe favorece a apresentação de universos fragmentários" em que são encontrados "personagens errantes" contrários a convenções de pensamento. ${ }^{28}$ Nos três contos, em especial em "Os sete sonhos", a parataxe é um recurso fundamental de construção. Diversos pensamentos do assassino de "O encontro", em particular em seu enunciado sobre o amor, são estranhos ao senso comum. A categoria "desregramento" é adequada para o processo de criação em "Raiz quadrada de menos um", cujos esboços de enredos não chegam a se completar, e também para os movimentos do sonhador em "Os sete sonhos", que não estão submetidos à explicitação de nenhuma norma prévia.

\footnotetext{
${ }^{25} I d .$, ib.., p. 158.

${ }^{26}$ GARCÍA-BERMEJO, José, ed. Francis Bacon. Rio de Janeiro: Civilização brasileira, s.d., p. 29.

27 BINES, Rosana Kohl. Na frequência de Samuel Rawet. Revista Brasileira. n. 71, 2012. p. 132.

${ }^{28}$ Idem, ibidem, p. 130.
} 
As formas narrativas, nesses contos de Samuel Rawet, são caracterizadas pela ênfase nas funções poética e expressiva da linguagem, reduzindo o alcance da função referencial. A indeterminação prevalece com relação à delimitação dos acontecimentos; as obras se valem de estratégias de choque, como deslocamentos bruscos no foco narrativo, e acontecimentos que expressam rupturas com premissas lançadas pelos narradores. Nos três casos, figuras de linguagem potenciam a polissemia dos textos, tendo a elipse uma destacada importância. Para citar Berta Waldman, as personagens de Rawet são construídas "à sombra da elipse". ${ }^{29}$

A aproximação entre os três contos permite observar um interesse, por parte de Rawet, em construir situações narrativas nas quais a diferenciação entre realidade e imaginação é problematizada. Entre um espaço intervalar e uma entrega à vida onírica, são constituídos a "irrealidade" da vida do tolo, o conhecimento estabelecido no sexto sonho, e os sentimentos do assassino, à revelia do homem que ele persegue.

Cabe reforçar a importância de uma das características mencionadas anteriormente: a ambiguidade entre a construção involuntária da vida onírica, referente ao movimento de constituição de sonhos, e a atitude que numera, situa e explora esse movimento. Essa ambiguidade, metaforicamente, pode se referir a uma tensão entre espontaneidade e controle, entre deslocamento e fixação. Essa tensão é muito importante no contexto dos anos 60, período que viveu rupturas e contradições, e foi atravessado por antagonismos entre forças de repressão e forças libertárias. Os antagonismos sociais impregnam a escrita de Samuel Rawet; nenhum desses contos propõe um pensamento sintético.

Jaime Ginzburg é professor de Literatura Brasileira na FFLCH - USP desde 2003. Pesquisador da CNPq. Autor de Crítica em tempos de violência (2012; $2^{\mathrm{a}}$ edição, 2017) e Literatura, violência e melancolia (2013), entre outros trabalhos. Coordenador do Grupo de Pesquisa Literatura e cinema no Brasil contemporâneo. Foi professor visitante em: UFMG, UNESP, University of Minnesota, King's College London e Universitat Bielefeld. Contato: ginzburg@usp.br

${ }^{29}$ WALDMAN, Berta. Entre passos e rastros. Op.cit., p. 72. 